International Journal of Instruction e-ISSN: 1308-1470 • www.e-iji.net
April 2019 • Vol.12, No.2

p-ISSN: 1694-609X

pp. 667-682

Received: 09/10/2018

Revision: 24/02/2019

Accepted: 02/03/2019

OnlineFirst: 17/03/2019

\title{
The Effect of THIEVES Strategy on EFL Learners' Reading Comprehension
}

\section{Elnaz Khataee}

Department of English Language, Faculty of Literature and Humanities, Hakim Sabzevari University, Sabzevar, Iran, elina.khataee@gmail.com

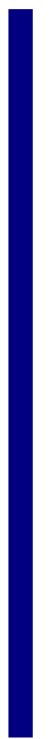

Reading comprehension is an important skill for EFL learners with fewer opportunities to communicate and gain knowledge in English. For a complete comprehension, the interaction between the student's prior knowledge and the content is necessary. Background knowledge plays the most important role in comprehension. The present study used a mixed method design to investigate the effect of THIEVES as an activating (schema activation) strategy on EFL learners' reading comprehension. Participants were 63 advanced students from an English language institute in Iran. First, they took the Oxford Quick Placement Test (OQPT) and then they were divided into experimental and control groups and the strategy was administered for the experimental group. Second, they were asked to fulfill a questionnaire about their difficulties through reading comprehension process. Based on the results of the questionnaire analysis, EFL learners confronted problems such as difficult content, unknown vocabulary, lack of background knowledge, and shortage of time. Results showed that there is a significant statistical difference between the scores of the control group and experimental groups. Besides, in the questionnaire learners of the experimental group indicated that THIEVES can help them to overcome their comprehension problems. Thus, it can be concluded that using THIEVES is beneficial in comprehension of expository texts.

Keywords: reading comprehension, THIEVES, background knowledge, activating strategy, comprehension problems

\section{INTRODUCTION}

Reading comprehension is one of the most essential skills for EFL learners that have less opportunities to communicate and improve in English. It is one of the necessary language skills for those who read to gain knowledge. Given the importance of reading comprehension skill, an important issue is the lack of using effective activating strategies based on students' needs to develop their reading comprehension skills.

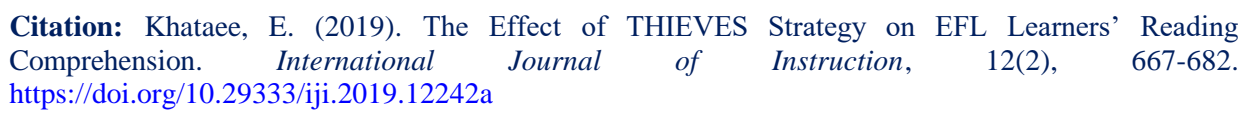


Reading skill is the most important in the four skills particularly when English is taught as a foreign language or as a second language (Carrell, Devine, \& Eskey, 1988; Tamsi, Zuhri \& Kurniasih, 2013; Zua, 2017). Many researchers have emphasized the significant role of reading comprehension skill for EFL learners (Alfassi, 2004; Dreyer \& Nel, 2003; Richards \& Renandya, 2002). It was believed that two sentences would best explain this statement that reading is the most important skill in language learning. First, because different pedagogical processes is served by written text, and second, it is one of the most important goals for most of the foreign language learners as they need this skill for obtaining knowledge from texts and fluency (Carrell, 1987).

Reading is a multidimensional skill and consists of a complicated mixture of linguistic, non-linguistic, and cognitive skills ranged from low-level processing capacities to a high-order knowledge of text illustration (Nassaji, 2003). The necessary knowledge for reading comprehension is classified into two types; the first type is related to form and has linguistic nature and the second type is about substance. It is involved with pragmatic and cultural knowledge (Eskey, 1986).

There are many studies about the factors affecting reading comprehension skill. For example, it is stated that fluency, which is a key factor and adequate improvement in learning to read English beyond the initial level, to a great extent depends on it (Snow, Burns, \& Griffith, 1998). Another factor is word recognition. Students read faster and have greater opportunity to gain meaning from the text as their automaticity in word recognition improves. When a reader stops to decode unfamiliar words, comprehension is disrupted because the reader needs to make connections between ideas within a text. If the speed of reading is too slow, it is difficult to make connections. Thus, accurate word recognition must be fast for fluency to occur during reading (Stricker, Roser, \& Martinez, 1998).

Other studies (Samuels, Shermer, \& Reinking, 1999) also mentioned the influence of memory as an important factor. These studies stated that decoding and comprehension for beginning reading is essential and this process highly depends on learners' memory. With practice, the novice reader becomes fluent. Vocabulary also affects students' comprehension in all types of texts. A study (Intarasombat, 2002), about the effects of vocabulary development on reading comprehension showed that many students had limited vocabulary knowledge and this area caused them problems in English reading comprehension.

In a more complete study (Tanghirunwat, 2003), Thai engineers reading manuals and textbooks were asked about their reading difficulties. For collecting the data, a questionnaire about the participants' difficulties on the content of texts, new vocabularies, and grammar was used. The results showed that Thai engineers' problems in vocabulary, grammar, and content made them unable to comprehend the texts. It was also revealed that the students had difficulties with vocabularies derived from new technologies and technical vocabularies. They had also difficulties with grammar in the areas of passive voice, complex and compound sentences, and complex phrases. 
Taken all the above studies into consideration, this statement comes to mind that a reader is not just a passive person who receives information from the text but the one who gives meaning to the text. It was indicated that reading comprehension is the ability to extract meaning from content and this ability includes comprehension, word recognition, and interpretation, and usage of every element in the text (Hengari, 2007).

Therefore, readers need to interact with the text to make sense of it. Reading performance, good or poor, reflects the ability of the readers in inferencing, predicting and using their previous knowledge during the reading comprehension process. Reading comprehension is "the process of simultaneously extracting and constructing meaning through interaction and involvement with written language" (p.11) and this process does not occur unless teachers identify and stop the causes of reading comprehension difficulties of learners (Snow, 2002).

Hence, the mental processes of the readers are important for researchers and it is proven by many researchers in the proposal of reading models, from bottom-up model (Carrell \& Eisterhold, 1983; Goodman, 1967; Hayes, 1991) to top-down models (Coady, 1979; Eskey, 1986; Goodman, 1967) to interactive ones (Gove, 1983; Rumelhart, 1980), and demonstrates the efforts that the theorists have delved into what happens when readers are reading and the importance of this fundamental skill is emphasized (Chang, 2004).

\section{THIEVES}

THIEVES is an activating strategy including seven steps with the purpose of providing necessary knowledge for students before going through the text. The strategy helps learners to activate their previous knowledge (schemata). In this strategy, students steal information from the text's Title, Headings, Introduction, Every first sentence, Visuals/Vocabulary, End-of chapter questions, and Summary before reading the whole text. Using this activating strategy helps students in recognizing important concepts and also argues about the ideas of a text passage (Manz, 2002).

\section{Steps of THIEVES}

1. Title: What information do I have about this topic? What is the relationship between this topic and the chapter? What point of view does the title present? What is the text's message?

2. Headings: What is the paragraph beneath this heading about? What information does this heading tell me? How can I change this heading into a question to be answered in the text? What can I understand from this heading?

3. Introduction: What information does the first paragraph provide about the whole chapter? Does the first paragraph introduce the chapter well? What does this introduction provide for me about what I will read? Do I have any knowledge about this topic?

4. Every first sentence in a paragraph: What does the whole chapter provide according to the first sentence in each paragraph?

5. Visuals and vocabulary: Are there any photographs, drawings, maps, charts, or graphs in the chapter? What can I understand from the visuals in the chapter? Is there a complete list of key vocabularies and definitions of the chapter? Are the 
important words of the chapter in boldface type throughout the chapter? Do I know the meanings of the words in boldface?

6. End-of-chapter questions: What do the questions want? What information do I need to answer the questions? What information can I learn from the questions? I should keep in mind the questions at the end of the chapter, so I can find where the information is located.

7. Summary: What do I learn and remember about the topics of the summary?

Reading is the fastest means of acquiring knowledge especially for EFL learners with fewer opportunities to communicate and gain knowledge in English. Developing reading comprehension skill is almost neglected in EFL classes in Iran, therefore this paper investigated the effect of THIEVES as an activating strategy to increase advanced EFL learners' comprehension.

Many studies (Graves \& Chen, 1995; Graves \& Cooke, 1980, Graves et al., 1983; Hudson, 1982; Johnson, 1981, 1982; Langer, 1984; Maghsoudi, 2012; Stevens, 1982; Taglieber et al., 1988) investigated the effect of pre-reading activities and strategies on EFL learners and suggested that these activities and strategies have a facilitative effect on text comprehension, but there are a few studies about the effects of THIEVES strategy especially for specific text types such as genres of expository. Therefore, this study focuses on the role of THIEVES as an activating strategy on EFL learners' reading comprehension.

Research questions are: (1) What is the impact of previewing expository texts by using THIEVES as an activating strategy on EFL learners' reading comprehension? (2) Does previewing expository texts through THIEVES help EFL learners in activating their prior knowledge for a better reading comprehension? (3) Does activating readers' prior knowledge through using an activating strategy enhance their comprehension of expository texts?

\section{LITERATURE REVIEW}

\section{THIEVES}

We cannot find many studies about the application of THIEVES strategy in teaching, but two important studies are mentioned here. This strategy is described for previewing texts and uses the acronym THIEVES: Title, Headings, Introduction, Every first sentence in a paragraph, Visuals and vocabulary, End of chapter questions, and Summary. The instructions for how to introduce and apply the strategy in elementary schools and colleges were explained (Manz, 2002).

In a study (Dohrenwend, 2010), THIEVES strategy was used in teaching readings for middle school students and it was applied with "side notes" and the side notes would be pointed out if the teacher was reading the book out loud to his learners such as figures, diagrams, captions, and vocabulary helpers. A blackboard was used to make the recordings available for the learners.

Another study (BC UDL Wiki, 2010) is an online lesson plan that was published on the British Colombia Universal Design for Learning wiki, based on the THIEVES 
previewing strategy. This study also had empirical findings about the effectiveness of THIVES strategy.

There is lack of research on the application of strategies such as THIEVES, especially in EFL instruction, therefore this study focuses on the Effect of this strategy on EFL learners' reading comprehension.

\section{Schema theory and Reading Comprehension}

"Schemata" is a term for mental patterns that form experiences, ideas and information; individuals' schemas change as they grow. The theoretical base of the background theory is schema theory (Craig, 1989). This word is defined as a structure of data for showing the concepts of genetic stored in the memory and schema theory explains how readers use their prior knowledge to comprehend and learn from text (Rumelhart, 1980). It is defined as knowledge that is used for comprehending texts (Medin \& Russ, 1992). It is also defined as an abstract knowledge frame for understanding (Anderson \& Pearson, 1984). It is applied when examining the importance of background knowledge in reading comprehension processes (Carrell, 1981; Hudson, 1982; Rumelhalt, 1980).

According to the basis of this theory, the written text does not carry meaning by itself and it just directs readers to how they should construct meaning from their own prior acquired knowledge. Students became discouraged when confronted by passages that consisted of too much unfamiliar vocabulary or had not been internalized. In these studies, presenting the words before starting the text was not effective for the students. Participants of these studies have mentioned that they had difficulties in understanding idioms because they could not be translated directly. Many other participants indicated that some of the materials and texts used in the classroom did not align with their schemata. Therefore, the absence of a familiar schema can be a serious barrier to comprehension (Carrell, 1987; Irwin, 1991).

Prior knowledge is the readers' background knowledge (previous knowledge), and the prior acquired knowledge structures are called schemata. This theory indicates that an interactive process between the text and the reader is needed for a complete comprehension. There should be a link between the readers' background knowledge and the text for the process of comprehension (Adams \& Collins, 1979; Barrlett, 1932; Rumelhart, 1980). So, the readers should have the ability to relate what they read to their previous knowledge.

\section{Background Knowledge and Reading Comprehension}

Background knowledge is also referred to as subject knowledge or topic familiarity of learners. Every material in reading comprehension needs a specific background knowledge. Different studies (Bensoussan, 1998; Khataee, 2018; Nelson, 1987; Pritchard, 1990; Tarchi, 2010) emphasized the importance of background knowledge in reading comprehension process and stated that relevant background knowledge would improve the performance of students in the process of reading comprehension. 
Prior knowledge is readers' crucial knowledge to reading and is classified into two types: 'knowledge of form' and 'knowledge of substance (Eskey, 1986). Expectations about the language of the text and making correct identifications of forms in text are provided by the knowledge of form. Knowledge of form consists of recognition of graphophonic, lexical, syntactic/semantic and rhetorical patterns of language (Eskey, 1986). Knowledge of substance, on the other hand, consists of pragmatic and subjectspecific information and provides expectations about the larger conceptual structure of the text. The knowledge of form is categorized into syntactic, semantic, orthographic and lexical knowledge (Rumelhart, 1994).

Readers construct meaning not only according to the text they are reading but also according to their knowledge and experiences. So, the learners' prior knowledge is an important factor that influences their comprehension. Different studies (Alptekin, 2006; Johnson, 1982; Lee, 2007) have showed the effectiveness of background knowledge on reading comprehension of EFL learners. For example, several studies investigated the importance of background knowledge according to the culture emphasized in the text and demonstrated that when readers are culturally familiar with the text, they have a better performance on comprehensive questions.

Background knowledge was more beneficial to low proficiency learners (Chan, 2003). It was also indicated that the topics of texts should involve a wider range of language proficiency levels. This happened because the majority of the researchers used advanced English proficiency learners as the participants of their studies (Alptekin, 2006; Chan, 2003; Priebe, Keenan, \& Miller, 2012).

\section{METHOD}

\section{Study Design}

This study applied a mixed method design to investigate the role of THIEVES as a prereading strategy in activating EFL learners' prior knowledge. EFL learners in experimental group was taught based on THIEVES which is a pre-reading strategy. The beneficial point about this strategy is that readers learn how to "steal" information from different sections and elements of the texts such as the Title, Headings, Introduction, Every first sentence, Visuals/Vocabulary, End-of chapter questions, and Summary before reading the whole text. EFL learners in control group received no treatment.

\section{Participants}

The participants were 63 Iranian EFL learners that were studying English as a foreign language in an institute. All the participants were native Persian speakers and had the same teacher. As the researcher looked for a homogeneous sample, she selected the sample randomly from 82 learners and from all intact classes. All of them were at the advanced level and had the same culture and also the same prior knowledge in English. Oxford Quick Placement Test (OQPT) was administered to ensure that all the learners were homogeneous. Therefore, learners chosen for the experimental group had equal chances for being chosen as representative of their genre. Then the participants were divided into the experimental and control groups. There were 32 students in 
experimental group and 31 students in control group (both randomly assigned). Their age ranged from 16 to 19 with a mean age of 17 years old and SD of 1.06 years.

\section{Instruments}

The instrumentation included two reading comprehension tests and a questionnaire (Zheng Lin, 2002). The first test was an expository text about "Organ Donation Program Moves". It had 1107 words and included 50 multiple choice questions with four options used. Each question had only one correct answer and the other three options were incorrect. The second expository text was about Halloween (one of the oldest holidays in the world and it is still celebrated in many European and American countries such as Mexico, Ireland, Canada, the United States and other Latin American countries). This one has about 472 words and included 50 multiple choice questions. The researcher was cautious to choose texts to be according to the participants' level of proficiency and background knowledge. The test was piloted at two different times: with 12 upper intermediate EFL students and with 10 advanced EFL students. The researcher made revisions according to the results of the pilot tests. The results showed that six items were inappropriate and were discarded and substituted by suitable items. Text difficulty and topic familiarity were also taken into consideration because these factors may affect their reading comprehension. The research also benefits a questionnaire (Zheng Lin, 2002) about the participants' difficulties through the process of reading comprehension without using this strategy in class. The instruments of the study were piloted two times and with two groups of EFL students before the study begins.

\section{Oxford Quick Placement Test}

To ensure that all participants of the study were at the same level and homogeneous, the Oxford Quick Placement Test (OQPT) consisting of 60 multiple-choice questions was administered to them. Based on the results of this test, there were 3 participants with extremely high level of proficiency that were excluded from the study.

\section{Data Collection Procedure}

The data were collected from 63 advanced EFL learners in an institute in Iran. For the purpose of this study, all the participants were asked to take Oxford Quick Placement Test (OQPT) to ensure that they are homogeneous (3 participants with extremely high level of proficiency that were excluded from the study). Then they were divided into two groups. 31 students were in control group and 32 students were in experimental group. The treatment which was used in this study was a background knowledge activation strategy called THIEVES. The aim of this pre-reading strategy is activating the readers' previous knowledge.

The texts were designed according to the students' level and were piloted two times first on 12 upper intermediate EFL students and second on 10 advanced EFL students. The questions (6 questions) that were too easy or too difficult were identified and replaced by more appropriate questions. Each test consists of an expository passage and participants had to answer 40 questions after each passage based on the information of the passage. 
Participants of the experimental group had three sessions of text previewing before reading texts and then in the fourth session they took comprehension tests based on the given passages. Before beginning reading texts, the learners previewed the text to bring out their prior knowledge about the topic, headings, and the content of the text. The teacher guided readers and tried to bring their previous knowledge to the surface.

The teacher began knowledge activation by asking the participants to look at the title, headings, and generally the text's arrangement carefully. Then the learners participated in class discussions about different parts of the texts under the teacher's guidance. Third, the teacher encouraged learners to share their comments and ideas to get as much as he could of what they know about the topic and headings of the texts.

The teacher used two reading comprehension texts followed by multiple choice questions for the experimental group according to THIEVES strategy during 4 sessions. The same texts were taught to control group, but no previewing strategy was used during the class sessions.

In addition, after the reading comprehension tests, finally, participants had to fulfill a questionnaire about their difficulties through the process of reading without using this strategy.

\section{FINDINGS AND DISCUSSION}

The aim of this study was to investigate the impact of schemata activation (prior knowledge or background knowledge) through using an activating strategy (THIEVES) on the reading comprehension of Iranian advanced EFL learners.

For conducting this study, the researcher believed that the sample must be homogeneous. Therefore, 63 students were selected randomly from 82 EFL advanced learners. After that, Quick Oxford Placement Test (QOPT) was administered to ensure that all the participants are homogeneous and then they were divided into two groups of experimental and control. There were 32 students in the experimental group who received the experiment's treatment which is THEIVES strategy. The control group had 31 participants and received no treatment. In the first section of the experiment, reading comprehension texts were taught to the control group without using any pre-reading strategy. Each text was presented in 2 sessions and as the researcher has prepared two texts, the treatment of the study was conducted during 4 sessions. Once the two texts had been performed, all the students' in both groups answered multiple choice questions based on the information of texts. The number of the correct answers were tabulated for both groups. 2 tables (Table 1 and Table 2) were used for the presentation of the revealed data that is the participants' scores in the multiple-choice questions which aims to test their reading comprehension ability. Based on the data in Table 1 the highest score for the experimental group in test 1 is 36 and the lowest one is 46 . For the control group, the highest mark is 32 and the lowest one is 15 . About test two, the highest score for the experimental group is 46 and the lowest one is 35. For the control group, the highest mark is 31 and the lowest one is 17 . 
The range of the scores for the experimental group in test one is from 36 to 46 and in test two is from 35 to 46 . For the control group, in test one it is from 15 to 32 and in test two it is from 17 to 31 . So Table (1) and (2) shows that the scores of the experimental group who received the treatment of the study is higher in both tests.

Table 1

Maximum and Minimum Scores

\begin{tabular}{cccccc}
\hline Group & $\mathrm{N}$ & Maximum & $\begin{array}{c}\text { Test one } \\
\text { Minimum }\end{array}$ & Maximum & $\begin{array}{c}\text { Test two } \\
\text { Minimum }\end{array}$ \\
\hline Experimental group & 32 & 46 & 36 & 46 & 35 \\
Control group & 31 & 32 & 15 & 31 & 17 \\
\hline
\end{tabular}

Calculating the mean scores of each group helps the researcher in conveying the difference between the scores obtained by the members of the groups. Table (2), shows the mean scores of the experimental and control group in each test:

Table 2

Results of Reading Comprehension Tests

\begin{tabular}{llllll}
\hline & \multicolumn{2}{c}{ Test one } & \multicolumn{2}{c}{ Test two } \\
Group & $\mathrm{N}$ & Mean & SD & Mean & SD \\
\hline Experimental group & 32 & 40.176 & 3.0338 & 39.8823 & 2.9681 \\
Control group & 31 & 23.6739 & 5.4095 & 23.4347 & 5.2941 \\
\hline
\end{tabular}

Based on table (3) and (4) there is a significant difference between the mean scores of both groups (experimental and control) in both tests. The mean scores of the control group in both tests (test one and test two) is significantly lower than the experimental group. Therefore, it can be concluded that the scores of the experimental group are higher or better than those of the control group.

Table (3) and (4) also show the results of using t-test. In this table, the standard deviation and standard error mean of both the experimental and control groups are exhibited. The results of the Independent samples t-test in Table (3) and (4) showing that in test one there is a significant statistical difference between the scores of control group (who did not receive the treatment) and experimental group who received the treatment. It can be seen that students of the experimental group had a great improvement after activating their background knowledge by using THIEVES as a previewing strategy $(\mathrm{t}=74.9126, \mathrm{p}<0.001)$ in test one and $(\mathrm{t}=76.0110, \mathrm{p}<0.001)$ in test two. This statistic indicates that background knowledge activation, by using a previewing strategy such as THIEVES enhances reading comprehension of advanced EFL readers.

Table 3

Independent Samples Test (Test one) 95\%Confidence interval of the difference

\begin{tabular}{lccccccc}
\hline Group & $\mathrm{t}$ & $\mathrm{df}$ & Sig. (2-tailed) & Mean difference & Std. Error Difference & Lower & Upper \\
\hline Experimental & 74.9126 & 31 & .000 & 40.176 & 0.5 & 39.0821 & 41.2698 \\
Control & 24.3665 & 30 & .000 & 23.6739 & 0.972 & 21.6896 & 25.6581 \\
\hline
\end{tabular}


Table 4

Independent Samples Test (Test two) 95\% Confidence interval of the difference

\begin{tabular}{lccccccl}
\hline Group & $\mathrm{t}$ & $\mathrm{df}$ & Sig. (2-tailed) & Mean difference & Std. Error Difference & Lower & Upper \\
\hline Experimental & 76.0110 & 31 & .000 & 39.8823 & 0.525 & 38.8121 & 40.9524 \\
Control & 24.6461 & 30 & .000 & 23.4347 & 0.951 & 21.4928 & 25.3765 \\
\hline
\end{tabular}

In section two, all the participants were asked to fulfill a questionnaire about their difficulties through reading comprehension. Participants of the experimental group were also asked to indicate which of their comprehension problems were removed through using this strategy (THIEVES) in the class.

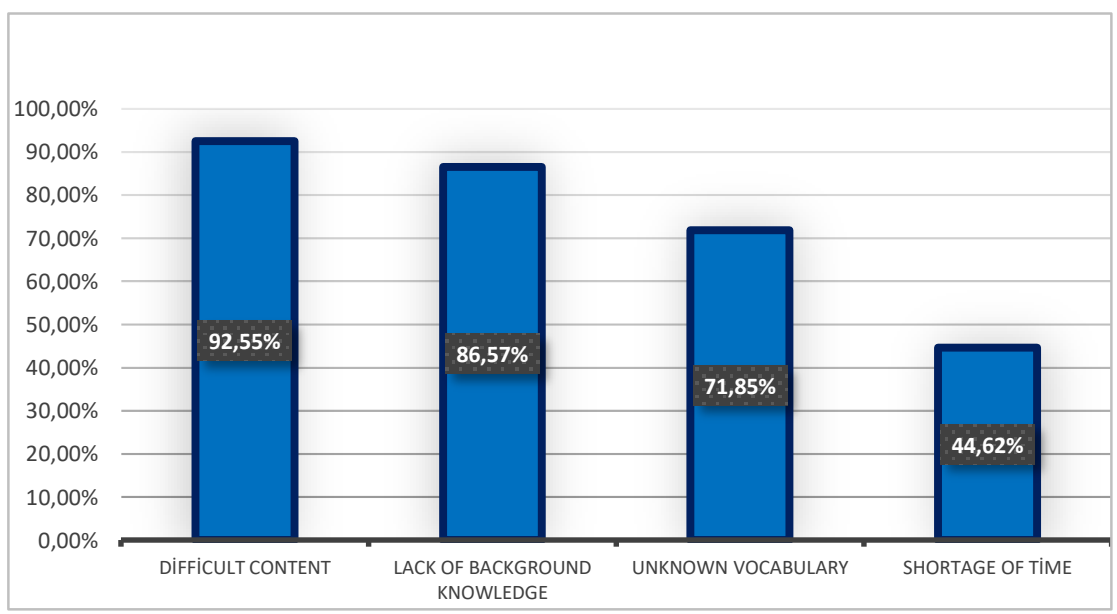

Figure 1

The Main Comprehension Problems of Experimental Group That Are Removed by Using THIEVES

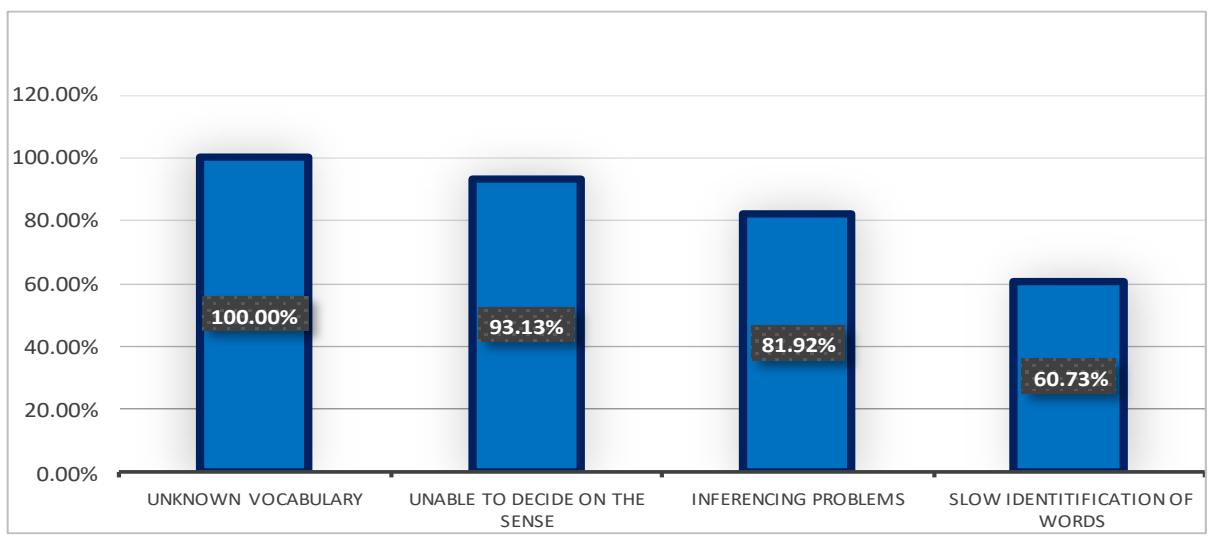

Figure 2

The Main Comprehension Problems of Control Group 
According to a study about the relationship between academic reading performance and vocabulary knowledge of students, it was shown that applying a method which contains the principles of both vocabulary depth and size measures is beneficial for improving the ability to predict reading performance. In this study those who didn't know the meaning of the words in the text can't answer the comprehension questions (Quian, 2002). By reviewing studies (Alderson, 1993; Berry, 1990), we can conclude that lexical knowledge is required to reading comprehension.

Difficult content, lack of background knowledge, shortage of time, slow identification of words, being unable to decide on sense and inferencing problems are other comprehension problems of the students. Similar to other studies (Speece \& Ritchey, 2005; Giangiacomo \& Navas, 2008; Snellings, van der Leij, de Jong, \& Blok, 2009; Silva \& Capellini, 2010), some of the participants of this study have also problems in reading speed and reading comprehension, it means that they don't know how to read quickly and how to comprehend the text well.

As shown in figure 1, participants of experimental stated that difficult content $(92.55 \%)$, lack of background knowledge $(86.57 \%)$, unknown vocabulary $(71.85 \%)$, and shortage of time $(44.62 \%)$ are the problems that they had overcome by using THIEVES. So this strategy was beneficial for them in overcoming their main comprehension problems.

Figure 2 shows the major comprehension problems of control group through reading comprehension. According to this figure, all the students of this group indicated that their main problem is unknown vocabulary. The students of the experimental group had this problem too, but THIEVES helps them to overcome this problem completely. The students of the control group had also problems such as being unable to decide on the sense $(93.13 \%)$, inferencing problems $(81.92 \%)$, and slow identification of words $(60.73 \%)$

This study revealed that prior knowledge has great positive impacts on reading comprehension (Alderson, 2000; Alptekin, 2006; Ketchum, 2006; Oller, 199; Pulido, 2003; Steffensen et al., 1979). It also emphasized the results of another study that indicated sentences with contents that are interesting for readers are more likely to be remembered than low-interest sentences (Anderson, et al. 1984). There are also several studies that have similar results. For example, in other studies, vocabulary size scores were used to consider the comprehension levels of learners (e.g., Alderson, 2000; Joshi, 2005; Ricketts, Nation, \& Bishop, 2007; Manyak \& Bauer, 2009). A strong relationship between different types of vocabulary size tests and reading comprehension tests was also found (Laufer, 1997). In general, results of the questionnaire showed that the main problem of most of the students is limited to vocabulary knowledge and lack of prior knowledge.

\section{CONCLUSION}

This study is an attempt to investigate the role of THIEVES as an activating or previewing strategy in activating EFL learners' background knowledge in advanced level. According to the findings of the study, previewing texts by using THIEVES strategy is beneficial for EFL learners and help them in overcoming their main reading 
comprehension problems. Therefore, background knowledge activation through using THIEVES strategy increases EFL learners' comprehension of the expository texts.

Other studies have the same results about the usefulness of applying, pre-reading, previewing, and activating strategies in EFL context. For instance, a study indicated that one of the major difficulties of the EFL learners' in reading comprehension is lack of using an effective previewing strategy and this leads to unsuccessful teaching in which students have fundamental comprehension problems (Tawalbeh \& Ismaiel, 2014). Therefore, THIEVES strategy can provide a suitable foreign language teaching situation for students.

In conclusion, the results from the present study elucidate that text previewing through using effective strategies such as THIEVES in reading expository texts enhances EFL learner' reading comprehension.

This strategy can also help students in overcoming problems such as limited vocabulary knowledge (unknown vocabulary), shortage of time, difficult or boring content, and also unfamiliar content.

\section{PEDAGOGICAL IMPLICATIONS}

First, background knowledge activation through text previewing and using THIEVES strategy helps EFL learners comprehend expository texts better. Therefore, applying an activating strategy such as THIEVES enhances EFL learners' involvement with text, gives them motivation, and also reduces their stress about what the content of the text is.

Second, it is beneficial for teacher trainers. It is necessary for them to be aware of the usefulness of activating strategies and emphasize on plans that help foreign language teachers in applying methods for activating prior knowledge before beginning reading texts. They should be cautious of the texts' characteristics and students' needs and then choose the most suitable strategy that fits students' needs.

Third, according to students' feedback in the questionnaire, they need assistance with difficult concepts and new vocabulary of texts. They indicated that difficult vocabulary poses fundamental problems for them. So, applying an appropriate pre-reading or activating strategy that help them in understanding new words before reading the text is necessary.

Finally, through using THIEVES strategy, students learn to participate in class discussions and work collaboratively to increase their knowledge.

\section{REFERENCES}

Adams, M. J., \& Collins, A. M. (Eds.). (1979). A schema-theoretic view of reading in Fredolle. Cambridge, NY: Norwood Ablex.

Alderson, J. C. (1993). The relationship between grammar and reading in an English for academic purposes test battery. In A new decade of language testing research: Selected papers from the 1990 Language Testing Research Colloquium (pp. 203-219). 
Alfassi, M. (2004). Reading to learn: Effects of combined strategy instruction on high school students. The Journal of Educational Research, 97(4), 171-185.

Alptekin, C. (2006). Cultural familiarity in inferential and literal comprehension in L2 reading. System, 34(4), 494-508.

Anderson, R. C., Reynolds, R. E., Schallert, D. L., \& Goetz, E. T. (1977). Frameworks for comprehending discourse. American Educational Research Journal, 14(4), 367-381.

BC UDL Wiki. (2010, August 7). BC Universal Design for Learning Project Wiki. Retrieved December 1, 2012, from THIEVES.doc: http://bcudl.pbworks.com/w/file/25947706/THIEVES.doc

Bensoussan, M. (1998). Schema effects in EFL reading comprehension. Journal of Research in Reading, 21(3), 213-227.

Berry, M. T. (1990). The relationship between analyzed knowledge of grammar and reading comprehension of authentic text at four levels of secondary school French. (Unpublished doctoral dissertation). The Ohio State University, The Ohio State, U.S.

Carrell, P. L. (1987). Content and formal schemata in ESL reading. TESOL Quarterly, 21(3), 461-481.

Carrell, P. L., Devine, J., \& Eskey, D. E. (Eds.). (1988). Interactive approaches to second language reading. Cambridge, NY: Cambridge University Press.

Chang-Chow, C. (2004). The effects of topic familiarity and language difficulty on situation-model construction by readers of Chinese as a foreign language. Doctoral Dissertation. University of Massachusetts, Amherst.

Chen, H. C., \& Graves, M. F. (1995). Effects of previewing and providing background knowledge on Taiwanese college students' comprehension of American short stories. TESOL Quarterly, 29(4), 663-686.

Coady, J. (1979). A psycholinguistic model of the ESL reader. Reading in a second language, 5-12.

Leonard W. R. \& Crawford M. H. (Eds.). (2002). Human biology of pastoral populations. Cambridge, NY: Cambridge University Press.

Craig, G. J. (Eds.). (1989). Human Development. Cambridge, NY: Prentice Hall.

Dohrenwend, P. (2010). Annotated reading. Science Scope, 54-57.

Dreyer, C., \& Nel, C. (2003). Teaching reading strategies and reading comprehension within a technology-enhanced learning environment. System, 31(3), 349-365.

Dubin, F., Eskey, D. E., Grabe, W., \& Savignon, S. (1986). Teaching second language reading for academic purposes. Reading, MA: Addison-Wesley.

Giangiacomo, M. C., \& Navas, A. L. (2008). The influence of operational memory on reading comprehension skills in 4th grade students, Revista da Sociedade Brasileira de Fonoaudiologia, 13(1), 69-74.

Goodman, K. S. (1967). Reading: A psycholinguistic guessing game. Literacy Research and Instruction, 6(4), 126-135. 
Gove, M. K. (1983). Clarifying teachers' beliefs about reading. The Reading Teacher, 37(3), 261-268.

Graves, M. F., Cooke, C. L., \& Laberge, M. J. (1983). Effects of previewing difficult short stories on low ability junior high school students' comprehension, recall, and attitudes. Reading Research Quarterly, 18(3), 262-276.

Graves, M. F., \& Palmer, R. J. (1981). Validating previewing as a method of improving fifth and sixth grade students' comprehension of short stories. Michigan Reading Journal, 15(1), 1-3.

Gredler, G. R. (2002). Snow, CE, Burns, MS, \& Griffin, P.(eds.) (1998). Preventing reading difficulties in young children. Washington, DC: National Academy Press.

Hayes, B. L. (1991). Effective strategies for teaching reading. Boston: Allyn \& Bacon.

Hengari, J. U. (2007). Identification of reading difficulties amongst grade 4 learners of the Arandis Primary School in the Erongo Region, Namibia. University of Namibia. Unpublished Research Report.

Hidi, S. (2001). Interest, reading, and learning: Theoretical and practical considerations. Educational Psychology Review, 13(3), 191-209.

Hudson, T. (1982). The effects of induced schemata on the "short circuit" in L2 reading: non-decoding factors in L2 reading performance. Language Learning, 32(1), 1-33.

Intarasombat, P. (2002). The effect of vocabulary development approach on Mathayomsuksa 4 students' English reading comprehension. Unpublished master's thesis, Khon kaen University, Khon kaen, Thailand.

Irwin, J. (1991). (2nd Ed). Teaching reading comprehension processes. New Jersey: Prentice Hall.

Jun Zhang, L., \& Bin Anual, S. (2008). The role of vocabulary in reading comprehension: The case of secondary school students learning English in Singapore. RELC Journal, 39(1), 51-76.

Khataee, E. (2018). Exploring the Effectiveness of Cultural Familiarity, Cultural Schemata and a Combination of Both. International Journal of English Language \& Translation Studies. 6(4). 01-06.

Langer, J. A. (1984). Examining background knowledge and text comprehension. Reading Research Quarterly, 19(4), 468-481.

Lee, S. K. (2007). Effects of textual enhancement and topic familiarity on Korean EFL students' reading comprehension and learning of passive form. Language Learning, 57(1), 87-118.

Lin, Z. (2002). Discovering EFL learners' perception of prior knowledge and its roles in reading comprehension. Journal of Research in Reading, 25(2), 172-190.

Maghsoudi, N. (2012). The impact of schema activation on reading comprehension of cultural texts among Iranian EFL learners. Canadian Social Science, 8(5), 196-201. 
Manz, S. L. (2002). A strategy for previewing textbooks: Teaching readers to become THIEVES. The Reading Teacher, 55(5), 434.

Martinez, M., Roser, N. L., \& Strecker, S. (1998). "I never thought I could be a star": A Readers Theatre ticket to fluency. The Reading Teacher, 52(4), 326-334.

Nassaji, H. (2003). Higher-level and lower-level text processing skills in advanced ESL reading comprehension. The Modern Language Journal, 87(2), 261-276.

Nelson, G. L. (1987). Culture's role in reading comprehension: A schema theoretical approach. Journal of Reading, 30(5), 424-429.

Nunan, D. (1991). Language teaching methodology (Vol. 192). New York: Prentice Hall.

Priebe, S. J., Keenan, J. M., \& Miller, A. C. (2012). How prior knowledge affects word identification and comprehension. Reading and Writing, 25(1), 131-149.

Pritchard, R. (1990). The effects of cultural schemata on reading processing strategies. Reading Research Quarterly, 25(4), 273-295.

Pulido, D. C. (2000). The impact of topic familiarity, L2 reading proficiency, and L2 passage sight vocabulary on incidental vocabulary gain through reading for adult learners of Spanish as a foreign language (Doctoral dissertation). Urbana: University of Illinois.

Pulido, D. (2007). The effects of topic familiarity and passage sight vocabulary on L2 lexical inferencing and retention through reading. Applied Linguistics, 28(1), 66-86.

Qian, D. D. (2002). Investigating the relationship between vocabulary knowledge and academic reading performance: An assessment perspective. Language Learning, 52(3), 513-536.

Richards, J. C., \& Renandya, W. A. (Eds.). (2002). Methodology in language teaching: An anthology of current practice. Cambridge, NY: Cambridge university press.

Rumelhart, D. (1980). Schemata: The building blocks of cognition. In. R. Spiro, B. Bruce and W. Brewer (eds.) Theoretical issues in reading comprehension.

Rumelhart, D. E. (1994). Toward an interactive model of reading. Newark: International Reading Association.

Samuels, S. J., Schermer, N., \& Reinking, D. (1992). Reading fluency: Techniques for making decoding automatic. What Research Has to Say about Reading. Reading Instruction, 2(1), 124-144.

Sánchez, E., \& García, J. R. (2009). The relation of knowledge of textual integration devices to expository text comprehension under different assessment conditions. Reading and Writing, 22(9), 1081-1108.

Silva, C., \& Capellini, S. A. (2010). Efficacy of the phonological remediation program and reading in the learning disorder, Pro-Fono, 22(2), 131-139. 
Snellings, P., van der Leij, A., de Jong, P. F., \& Blok, H. (2009). Enhancing the reading fluency and comprehension of children with reading disabilities in an orthographically transparent language. Journal of Learning Disabilities, 42(4), 291-305.

Snow, C. (2002). Reading for understanding: Toward an $R \& D$ program in reading comprehension. California: Rand Corporation.

Speece, D. L., \& Ritchey, K. D. (2005). A longitudinal study of the development of oral reading fluency in young children at risk for reading failure. Journal of Learning Disabilities, 38(5), 387-399.

Stevens, K. C. (1982). Can we improve reading by teaching background information? Journal of Reading, 25(4), 326-329.

Tamsi, R. K. (2013). The implementation of skimming and scanning strategies in teaching reading narrative text to the tenth-grade students of SMAN 21 SURABAYA. Retain, 1(2), 1-7.

Tanghirunwat, C. (2003). The reading difficulties faced by Thai engineers in telecommunication industry in reading English technical textbooks and manuals. Unpublished master's thesis, The University of Thai Chamber of Commerce, Bangkok, Thailand.

Taglieber, L. K., Johnson, L. L., \& Yarbrough, D. B. (1988). Effects of preceding activities on EFL reading by Brazilian college students. TESOL Quarterly, 22(3), 455472 .

Tarchi, C. (2010). Reading comprehension of informative texts in secondary school: A focus on direct and indirect effects of reader's prior knowledge. Learning and Individual Differences, 20(5), 415-420.

Tawalbeh, T., \& Ismaiel, N. (2014). Effectiveness of a Metacognitive Reading Strategies Program for Improving Low Achieving EFL Readers. International Education Studies, 8(1), 43-56.

Yuet, C., \& Chan, H. (2003). Cultural content and reading proficiency: A comparison of mainland Chinese and Hong Kong learners of English. Language Culture and Curriculum, 16(1), 60-69.

Zua, B. (2017). Reading: When and Why. Journal of Education \& Social Policy, 4(2), 128-132. 